\title{
Correlation-based Genetic Algorithm for Real-parameter optimization
}

\author{
Arghya Kundu \\ Lexmark International Pvt. Ltd. \\ Kolkata, India \\ E-mail: akundu@lexmark.com
}

\author{
Sougata Laha \\ School of Computer Engineering \\ Nanyang Technological University, Singapore \\ E-mail: sougata001@e.ntu.edu.sg
}

\author{
Athanasios V. Vasilakos \\ Department of Computer Science, \\ Electrical and Space Engineering \\ Lulea University of Technology, Sweden \\ E-mail: athanasios.vasilakos@1tu.se
}

\begin{abstract}
We propose a genetic algorithm (GA) by taking into account the correlation between the current best candidate with the other candidates in the population.In this paper we propose a new selection operator and in addition we have designed a prediction operator which works on an archive of selected candidates. We test our proposed algorithm on the problem definitions for the CEC 2014 special session and competition on single objective real-parameter numerical optimization.
\end{abstract}

\section{INTRODUCTION}

Evolutionary algorithms (EAs) are population-based metaheuristic optimization algorithms that mimic the process of natural evolution. One such EA is GA, a probabilistic search algorithm proposed by John Holland in 1975 [1] and were described as adaptive heuristic search algorithms [2] based on the evolutionary ideas of natural selection and natural genetics by David Goldberg.

The basic idea behind algorithms like GA aspires from man's understanding of nature. Nature has always found its way to the best possible solution of any particular problem. Survival of a species is one such problem whose solution is found by the iterative generation of new fitter individuals i.e by Darwinian evolution. This motivated the creation of GA, which tries to imitate this natural process into a computational paradigm.

GA maintains a population of candidate solutions (as individuals) and improves them sequentially based on fitness function. It works with a population of individuals represented by chromosomes. Each chromosome is a coded representation of a possible solution. The fitness of each chromosome is the value of the function to be optimized when the chromosome is given as input. The population undergoes transformation using three primary genetic operators:

- selection individual to be parents,

- crossover between parents to produce offspring, and

- mutation of the offspring

from which new generations evolve. This process continues till the optimum value of the considered function is achieved. Interested readers are referred to [3]-[6].

The first step is selection of individuals for the production of the next generation and the second step is manipulation of the selected individuals to form the next generation by crossover and mutation operators. The selection technique determines which individuals are chosen for mating and how many offspring each selected individual produces. The main principle of selection strategy is the fitter individual is, higher is its chance of being selected" [7]. Generally, crossover and mutation exploit and explore the search space respectively, whereas selection reduces the search area within the population by discarding poor solutions. The selection operator is as important as other operators in GAs. A good search technique must find a good trade-off between exploration and exploitation in order to find a global optimum [6]. Hence, it is important to find a balance between exploration and exploitation within the mechanism of the selection.

The most often used selection schemes are proportional selection methods, such as Roulette Wheel Selection (RWS), Stochastic Reminder Roulette Wheel Selection (SRRWS), and Stochastic Universal Sampling (SUS). There exist a number of studies on the selection operators. Miller and Goldberg studied the performance of tournament selection and developed a model for selection pressure of tournament selection [8]. Arumugam [9] proposed single and two level hybrid selection operators that were a combination of both roulette wheel and tournament selection operators. Kaya [10] developed the Back Controlled Selection Operator (BCSO) which fitness values of the individual are compared with the fitness value in the previous generation. This technique primarily considers the fitness value of an individual to make the decision of whether it would be a parent or not, and does not account the importance each gene. We took inspiration from the above fact and have proposed a new selection operator (named Correlation Selection CS) that takes into consideration each gene of a chromosome, amount of similitude between the individuals and their fitness values.

Interestingly, GAs have shown to maintain archives of individuals from previous generation to further assist in search moves, like JADE [11], SHADE [12]. The idea is to apply these archives either in ongoing search or in the later generations. Also, hybridization of GA with other techniques (local search) in presence of archive [13], have shown to improve performance in many real-life problems. The purpose of this archive varies from algorithm to algorithm. Mostly they are used for exploitation, in order to to maintain diversity. While there are few algorithms that uses Archives for quick convergence. It has been shown that maintaining external Archives significantly increases the chance of finding a optimum solution in the 
required time frame [12]. We got motivated from this and have used 2 Archives, one for exploration and the other for exploitation.

Our proposed algorithm is called Correlation-based GA with Archive (Corr-GAA). It focuses on information sharing between the best-fit individual in the population and the other individuals. We have also incorporated a selection operator, that takes into account the amount of similitude between the individuals. The algorithm has been implemented for solving the CEC 2014 competition problems on real-parameter optimization.

The rest of the paper is ordered as follows. Section II describes our proposed algorithm and its components. The problems used are detailed in Section III . Section IV briefly states the experimental setup corresponding to the requirements of the competition, experimental results are discussed and observation on parameter variations are noted. Finally, the conclusions are given in section $\mathrm{V}$.

\section{Our Proposed Algorithm}

Corr-GAA predicts best-fit candidates and takes into account the candidates which are far away from the current best candidate but whose fitness is above the current average fitness. The integral part of Corr-GAA is the amount of likeness between two individuals. We call this the correlation coefficient (see Eq. 6).

\section{A. Initialization of trial population}

Analogous to population based metaheuristics, the basic GA initiates the search process by instantiation of a trial population $\mathbf{X}$ consisting of $N p$ individuals each representing a $D$-dimensional real vector and is designated as $X_{i, G}=$ $\left\{x_{1, i, G}, x_{2, i, G}, \ldots x_{D, i, G}\right\}$ at generation $\mathrm{G}$ and $i=$ $\{1,2, \ldots, N p\}$.

The initial population is generated by using uniform random number so as to ensure a better spread across the search space bounded by $X_{\text {min }}=\left\{x_{1, \min }, x_{2, \min }, \ldots, x_{D, \min }\right\}$ and $X_{\max }=\left\{x_{1, \max }, x_{2, \max }, \ldots, x_{D, \max }\right\}$. The initialization at generation $G=0$ takes place as

$$
x_{j, i}=x_{j, \min }+\operatorname{rand}(0,1) \times\left(x_{j, \max }-x_{j, \min }\right)
$$

where $j$ is the problem parameter (dimension) that can take values from $[1,2, \ldots, D], i$ is the running index $i \in[1, . . N p]$ and $\operatorname{rand}(0,1)$ is an uniform random number taken lying in the range $[0,1]$.

Now we focus on the external archives/ tables used by Corr-GAA (Section II-B) and the calculation of correlation coefficient (Section II-C).

\section{B. External Archives}

Corr-GA maintains three external archives, whose purpose will be detailed later.

- $T_{b}$ (Best-Candidate Table) is a table of length $T$, containing the best candidates of ongoing generation.
- $T_{x b}$ (Probable Best-Candidate Table) is a table of length $T$, containing the predicted best candidates by observing $T_{b}$.

- $T_{e}$ Correlated-Candidate is a table of length $R$, containing candidates least correlated with the best candidate but is above average fitness.

- $W$ contains the relative weight of each dimension,

where $T$ and $R$ are fractions of the maximum number of generations $G_{\max }$ such that $R<2 T$.

\section{Correlation Coefficient Calculation}

Let two candidates whose correlation coefficient (CC) is to be calculated be represented as follows,

$$
X_{A}:\left\{x_{1, A}, x_{2, A}, x_{3, A}, \ldots, x_{D, A}\right\}
$$$$
X_{B}:\left\{x_{1, B}, x_{2, B}, x_{3, B}, \ldots, x_{D, B}\right\}
$$

where, $D$ is the dimension of each candidate solution.

Firstly a weighted square sum and square sum of each dimension between the candidates are calculated along with a ratio of the fitness value of the individuals as described,

$$
\begin{gathered}
\text { Weighted Square Sum (WSS) }=\sum_{i=1}^{K}\left(W_{i} \times\left|x_{i, A}-x_{i, B}\right|^{2}\right) \\
\text { Square Sum (SS) }=\sum_{i=1}^{K}\left|x_{i, A}-x_{i, B}\right|^{2} \\
\text { Fitness Ratio (FR) }=\frac{\left|f i t\left(X_{A}\right)\right|}{\left|f i t\left(X_{B}\right)\right|}
\end{gathered}
$$

where $f i t\left(X_{A}\right)$ and $f i t\left(X_{B}\right)$ are the fitness values of population members $X_{A}$ and $X_{B}$ respectively, and $W$ is an array of length $D$ (number of variables) containing the relative weight of each variable (between $[0,1]$ ). This is modified at the end of each run. $F R$ is further modified as

$$
F R= \begin{cases}F R, & \text { if } F . R<1, \\ 1, & \text { otherwise. }\end{cases}
$$

Now $\mathrm{CC}$ of $B$ with respect to $A$ is derived as follows,

$$
C C=\left(1-\sqrt{\frac{W S S}{S S} \times F . R}\right)
$$

\section{Relative weight calculations}

Initially at the start of each run all the variables are assumed to be equally important with $W_{i}=0.5$. $W_{i}$ values are modified each time $C C$ is calculated, as follows.

Firstly a factor $\left(F_{i}\right)$ is calculated.

$$
F_{i}=\frac{\left|a_{i}-b_{i}\right|}{|f i t(A)-f i t(B)|}
$$

If the fitness values are equal then $W_{i}$ is not modified. Otherwise, if $F_{i}<1$,

$$
W_{i}=W_{i}+\frac{\left(1-W_{i}\right)}{2^{F_{i}}}
$$

or if $F_{i}>1$,

$$
W_{i}=W_{i}-\frac{W_{i}}{2^{\frac{1}{F_{i}}}}
$$




\section{E. Selection method used}

We have proposed a new selection operator (Correlation Selection CS) which is based on the likeness of a candidate with the best-fit candidate $X_{b e s t, G}$ in the population. The procedure is as follows:

Uniformly randomly select a candidate whose fitness is above the average fitness of the population. Then find its CC with respect to the current best candidate by using Eq. 6. After $N p / 8$ iterations, the candidate with the highest CC is returned. This selection mechanism ensures that fitter members survive in a population sample of constant size $N p$ and at the same time diversity in the population is maintained. The pseudocode is given in Algorithm 1.

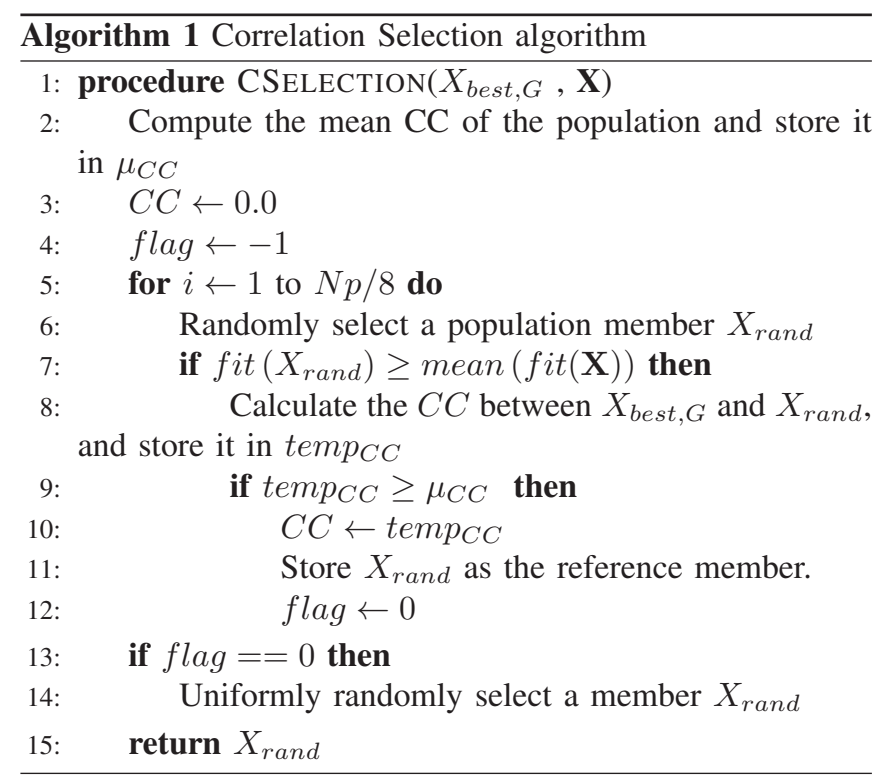

\section{F. Selection of Parents}

Selection of a pair of parent chromosomes from the mating pool is done by using the selection operator described earlier in (Section II-E). Selection is done "with replacement," thus the same chromosome can be selected more than once to become a parent. The mating pool contains only the individuals of the current population until the External Tables are full, i.e till $2 T$ runs. From $(2 T+1)^{\text {th }}$ run, the mating pool also contains the individuals from Tables $T_{x b}$ and $T_{e}$. From then onward, one individual is selected from the current population by using the selection operator described earlier and the other is selected uniformly randomly from Table $T_{e}$ (with probability $P_{e}$ ) or Table $T_{x b}$ (with probability $P_{x b}$ ) or from the current population by using the selection operator described earlier. The selection mechanism has been outlined in Algorithm 2.

\section{G. Crossover between Parents}

We have used Blend Crossover (BLX- $\alpha$ ) as shown in Figure 1 from [14], with a fixed crossover probability $P_{c}$. The BLX$\alpha$ operator has associated a high exploration, which induces a high diversity among the descendants. Therefore, this operator

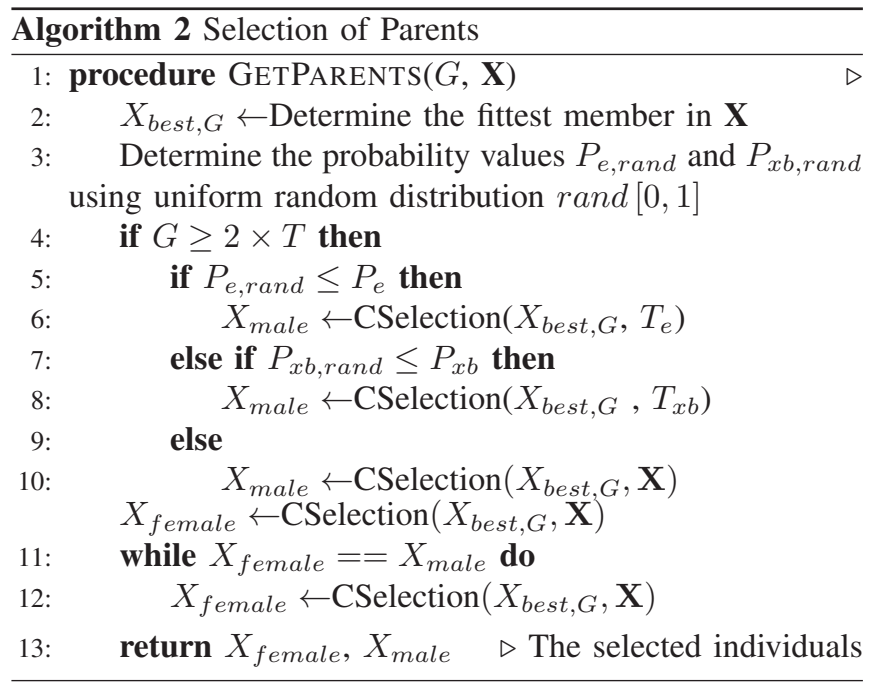

allows big differences among the descendants and among them and their parents. This crossover operates as follows,

Let us assume that $X_{A}:\left\{x_{1, A}, x_{2, A}, x_{3, A}, \ldots, x_{D, A}\right\}$ and $X_{B}:\left\{x_{1, B}, x_{2, B}, x_{3, B}, \ldots, x_{D, B}\right\}$ are two real-coded chromosomes to be crossed. Then BLX$\alpha$ generates two offspring $H_{1}$ and $H_{2}$, where $H_{N}=\left\{h_{1, N}, h_{2, N}, h_{3, N}, h_{4, N}, \ldots, h_{D, N}\right\} ; N=1,2$ such that $h_{i, N}$ is a randomly (uniformly) chosen number from the interval $\left[C_{\min }-I \alpha, C_{\max }+I \alpha\right]$. Note that here $C_{\max }=\max \left\{x_{i, A}, x_{i, B}\right\}$ and $C_{\min }=\min \left\{x_{i, A}, x_{i, B}\right\}$ and $I=C_{\max }-C_{\min }$.

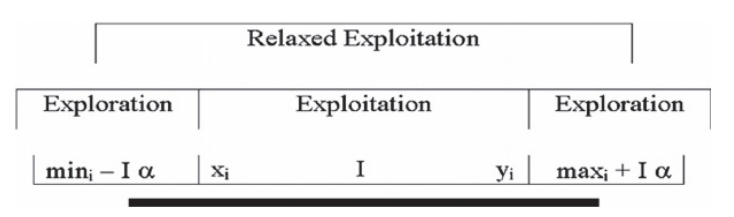

Fig. 1. Pictorial representation of blended crossover alpha (BLX- $\alpha$ )

It is important to emphasize that this crossover operator is based on the random generation of genes from the associated neighbourhood of the genes in the parents. With this technique for the generation of genes, offspring are generated can defer among them and also among them and their parents.

Before $2 T$ generations, crossover is done between parents from the current population. But after $2 T$ runs, individuals from the external archives $\left(T_{x b}\right.$ and $\left.T_{e}\right)$ may participate. As described in Algorithm 3.

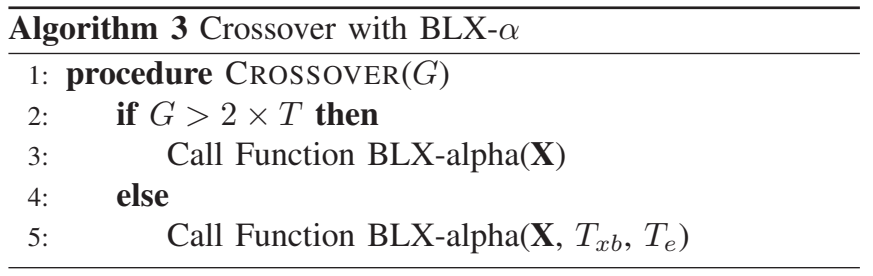




\section{H. Mutation of offspring}

Unlike general GA framework, in this algorithm we have used mutation operator that is generally deployed in Differential Evolution (DE) algorithm [15]. The mutation operation works as follows: once the offspring are generated, their genes are mutated with fixed Mutation Probability $P_{m}$ as per Eq. 10,

$$
x_{i}=x_{\min }+\operatorname{rand}(0,1) \times\left(x_{\max }-x_{\min }\right)
$$

where, the running index $i \in[1, . . N p]$ and $\operatorname{rand}(0,1)$ is an uniform random number taken lying in the range $[0,1]$. This guarantees the maximum exploration of the search space. The convergence rate by using the external archives is high thus the balance between exploration and exploitation of the overall algorithm is maintained.

\section{External Archives updating}

At the end of each rum the Tables $T_{b}, T_{x b}$ and $T_{e}$ are updated as detailed,

- $T_{b}$ : The current best-fit candidate in the population is stored in $T_{b}$. If $T_{b}$ is full (i.e. after each $T$ runs) the oldest is discarded.

- $T_{x b}: T_{x b}$ is updated after $T_{b}$ is full i.e. after $T$ runs. A probable good candidate is predicted by observing the candidates in $T_{b}$, and is stored in $T_{x b}$ [Section II-J]

- $T_{e}$ : The candidate with above average fitness and with the least $C C$ with respect to the current best-fit candidate is found out and stored here. If $T_{e}$ is full (i.e. after each $R$ runs) the oldest is discarded.

\section{J. Prediction of "good" candidate}

Firstly a random individual is selected uniformly from Table $T_{b}$ (Best-Candidate Table), say $X_{B}$. Let the predicted candidate is $X_{A}=\left\{x_{1, A}, x_{2, A}, x_{3, A}, \ldots, x_{D, A}\right\}$, where $D$ is the problem dimensionality.

Say, $X_{B}=\left\{x_{1, B}, x_{2, B}, x_{3, B}, \ldots, x_{D, B}\right\}$ and $X_{C}=$ $\left\{x_{1, C}, x_{2, C}, x_{3, C}, \ldots, x_{D, C}\right\}$, where $X_{C}$ is the individual right after $X_{B}$ in the Table $T_{b}$. Now the components of a temporary good solution is calculated as,

$$
x_{i, T e m p}=\frac{f i t\left(X_{B}\right) \times x_{i, B}+f i t\left(X_{C}\right) \times x_{i, C}}{f i t\left(X_{B}\right)+f i t\left(X_{C}\right.}
$$

Now, Two variables are calculated rate and direction, which depicts the rate of change of the best-candidates per run and the direction the change is taking place respectively.

$$
\begin{gathered}
\text { Rate }=x_{i, B}-x_{i, C} \\
\text { Direction }=f i t\left(X_{B}\right)-f i t\left(X_{C}\right)
\end{gathered}
$$

Once this factors are calculated, the components of the predicted best candidate are calculated as follows,

$$
x_{i, A}= \begin{cases}x_{i, \text { Temp }}-\left(\text { rate } \times x_{i, B}\right), & \text { if Direction }>0, \\ x_{i, \text { Temp }}+\left(\text { rate } \times x_{i, B}\right), & \text { otherwise. }\end{cases}
$$

\section{PRoblem DeFinitions}

The performance of the proposed algorithm is analysed by solving the set of problem definitions and evaluation criteria for the CEC 2014 special session and competition on single objective real-parameter numerical optimization [16]. The characteristics of the problems are briefly detailed below.

\section{- Unimodal Functions}

1) Rotated High Conditioned Elliptic Function

2) Rotated Bent Cigar Function

3) Rotated Discus Function

\section{- Simple Multimodal Functions}

1) Shifted and Rotated Rosenbrocks Function

2) Shifted and Rotated Ackleys Function

3) Shifted and Rotated Weierstrass Function

4) Shifted and Rotated Griewanks Function

5) Shifted Rastrigins Function

6) Shifted and Rotated Rastrigins Function

7) Shifted Schwefels Function

8) Shifted and Rotated Schwefels Function

9) Shifted and Rotated Katsuura Function

10) Shifted and Rotated HappyCat Function

11) Shifted and Rotated HGBat Function

12) Shifted and Rotated Expanded Griewanks plus Rosenbrocks Function

13) Shifted and Rotated Expanded Scaffers F6 Function

\section{- Hybrid Function 1}

1) Hybrid Function $1(\mathrm{~N}=3)$

2) Hybrid Function $2(\mathrm{~N}=3)$

3) Hybrid Function $3(\mathrm{~N}=4)$

4) Hybrid Function $4(\mathrm{~N}=4)$

5) Hybrid Function $5(\mathrm{~N}=5)$

6) Hybrid Function $6(\mathrm{~N}=5)$

\section{- Composition Functions}

1) Composition Function $1(\mathrm{~N}=5)$

2) Composition Function $2(\mathrm{~N}=3)$

3) Composition Function $3(\mathrm{~N}=3)$

4) Composition Function $4(\mathrm{~N}=5)$

5) Composition Function $5(\mathrm{~N}=5)$

6) Composition Function $6(\mathrm{~N}=5)$

7) Composition Function $7(\mathrm{~N}=3)$

8) Composition Function $8(\mathrm{~N}=3)$

This benchmark is composed of 30 functions defined in 3 dimensions $D=\{10,30,50\}$. Following the requirements of the competition, each function is executed 51 times.

\section{Evaluating CORR-GAA ON CEC 2014 BENCHMARK SET}

Corr-GAA was implemented with Visual C++ 2015 and was run on a Intel (R) CoreTM i5 CPU 760@2.80 GHz machine with 2 GB RAM running on Windows 7 Enterprise OS.

The algorithm was run 51 times for each test problem, where the stopping criterion was to run for up to $10000 D$ fitness evaluations (FFEs), where $D$ was 10,30 and 50 variables. For 
all test problems, all variables were randomly initialized with $x_{j, \max }=100$ while $x_{j, \min }=-100$.

All parameters were initialized as follows: $P_{c}=0.9, P_{m}=$ $0.051, P_{x b}=0.6, P_{e}=0.25, \mathrm{~T}=$ Total Runs $\times 0.4$ and $\mathrm{R}$ $=$ Total Runs $\times 0.2$.

\section{A. Results for $10 D$}

The function error from the optimal solution $f\left(x^{i}\right)+f\left(x^{*}\right)$ ,for each problem, of the proposed algorithm for the 10D test problems are shown in Table I, where $x^{*}$ is the global optimum of the considered test function, and $x^{i}$ is the best solution achieved by Corr-GAA.

It can be seen from the results that the best solution is near the global optima for multimodular functions. For composite functions the solutions are quite good as well.

TABLE I

RESULTS FOR 10D

\begin{tabular}{|c|c|c|c|c|c|}
\hline Func. & Best & Median & Average & Worst & Std. \\
\hline 1 & $1.4979 \mathrm{E}+04$ & $1.1605 \mathrm{E}+07$ & $1.2975 \mathrm{E}+06$ & $2.3633 \mathrm{E}+06$ & $2.8248 \mathrm{E}+06$ \\
\hline 2 & 4.9253E-01 & $7.1773 \mathrm{E}+03$ & $4.9639 \mathrm{E}+02$ & $1.4489 \mathrm{E}+03$ & $1.7934 \mathrm{E}+03$ \\
\hline 3 & $4.5507 \mathrm{E}+00$ & $2.6838 \mathrm{E}+04$ & $2.5943 \mathrm{E}+03$ & $4.7976 \mathrm{E}+03$ & $5.8483 \mathrm{E}+03$ \\
\hline 4 & $1.9326 \mathrm{E}-02$ & $4.6625 \mathrm{E}+00$ & $1.4391 \mathrm{E}+01$ & $3.5015 \mathrm{E}+01$ & $1.4731 \mathrm{E}+01$ \\
\hline 5 & $1.9314 \mathrm{E}+01$ & $2.0005 \mathrm{E}+01$ & $2.0008 \mathrm{E}+01$ & $2.0049 \mathrm{E}+01$ & $1.4976 \mathrm{E}-02$ \\
\hline 6 & $2.0750 \mathrm{E}-03$ & $1.4482 \mathrm{E}+00$ & $1.6695 \mathrm{E}+00$ & $6.5363 \mathrm{E}+00$ & $1.3817 \mathrm{E}+00$ \\
\hline 7 & $0.0000 \mathrm{E}+00$ & $5.8989 \mathrm{E}-02$ & $6.1148 \mathrm{E}-02$ & 2.4361E-01 & $4.5625 \mathrm{E}-02$ \\
\hline 8 & $0.0000 \mathrm{E}+00$ & $0.0000 \mathrm{E}+00$ & $0.0000 \mathrm{E}+00$ & $0.0000 \mathrm{E}+00$ & $0.0000 \mathrm{E}+00$ \\
\hline 9 & 9.9496E-01 & $9.9496 \mathrm{E}+00$ & $1.0966 \mathrm{E}+01$ & $2.4874 \mathrm{E}+01$ & $5.1978 \mathrm{E}+00$ \\
\hline 10 & $6.2454 \mathrm{E}-02$ & $2.1413 \mathrm{E}-01$ & 2.2379E-01 & 4.6534E-01 & 8.5327E-02 \\
\hline 11 & $1.6775 \mathrm{E}+01$ & $4.5508 \mathrm{E}+02$ & $4.6417 \mathrm{E}+02$ & $1.0568 \mathrm{E}+03$ & $2.2133 \mathrm{E}+02$ \\
\hline 12 & 3.7294E-02 & 1.8786E-01 & 2.0997E-01 & 4.6865E-01 & $1.0535 \mathrm{E}-01$ \\
\hline 13 & $4.3488 \mathrm{E}-02$ & $1.6178 \mathrm{E}-01$ & $1.6896 \mathrm{E}-01$ & $3.1109 \mathrm{E}-01$ & 6.5494E-02 \\
\hline 14 & $9.4205 \mathrm{E}-02$ & $3.5102 \mathrm{E}-01$ & 3.3747E-01 & 4.8261E-01 & 9.5167E-02 \\
\hline 15 & 3.7677E-01 & $1.2160 \mathrm{E}+00$ & $1.2449 \mathrm{E}+00$ & $2.8923 \mathrm{E}+00$ & 4.5844E-01 \\
\hline 16 & $1.2680 \mathrm{E}+00$ & $2.5947 \mathrm{E}+00$ & $2.4699 \mathrm{E}+00$ & $3.2003 \mathrm{E}+00$ & 4.6237E-01 \\
\hline 17 & 4.0404E+02 & $5.6623 \mathrm{E}+04$ & $8.8058 \mathrm{E}+04$ & 4.7843E+05 & $1.0649 \mathrm{E}+05$ \\
\hline 18 & $2.2332 \mathrm{E}+01$ & $5.7760 \mathrm{E}+03$ & $8.6095 \mathrm{E}+03$ & $3.2197 \mathrm{E}+04$ & $8.5000 \mathrm{E}+03$ \\
\hline 19 & 8.8073E-02 & $1.0022 \mathrm{E}+00$ & 7.8868E-01 & $1.5169 \mathrm{E}+00$ & 4.3281E-01 \\
\hline 20 & $1.8966 \mathrm{E}+00$ & 4.4430E+03 & $6.4772 \mathrm{E}+03$ & $2.9689 \mathrm{E}+04$ & $7.2317 \mathrm{E}+03$ \\
\hline 21 & $5.2405 \mathrm{E}+01$ & $4.5021 \mathrm{E}+03$ & $6.8009 \mathrm{E}+03$ & $2.6704 \mathrm{E}+04$ & $7.4059 \mathrm{E}+03$ \\
\hline 22 & 7.4683E-04 & 8.2595E-01 & $3.5486 \mathrm{E}+01$ & $1.4630 \mathrm{E}+02$ & $6.1727 \mathrm{E}+01$ \\
\hline 23 & $3.2946 \mathrm{E}+02$ & $3.2946 \mathrm{E}+02$ & $3.2946 \mathrm{E}+02$ & $3.2951 \mathrm{E}+02$ & $1.0578 \mathrm{E}-02$ \\
\hline 24 & $1.1063 \mathrm{E}+02$ & $1.2622 \mathrm{E}+02$ & $1.2680 \mathrm{E}+02$ & $1.5067 \mathrm{E}+02$ & $9.7329 \mathrm{E}+00$ \\
\hline 25 & $1.1764 \mathrm{E}+02$ & $2.0099 \mathrm{E}+02$ & $1.7996 \mathrm{E}+02$ & $2.0332 \mathrm{E}+02$ & $2.7413 \mathrm{E}+01$ \\
\hline 26 & $1.0003 \mathrm{E}+02$ & $1.0017 \mathrm{E}+02$ & $1.0018 \mathrm{E}+02$ & $1.0037 \mathrm{E}+02$ & $9.3364 \mathrm{E}-02$ \\
\hline 27 & $2.2267 \mathrm{E}+00$ & $3.6623 \mathrm{E}+02$ & $3.2854 \mathrm{E}+02$ & $4.5350 \mathrm{E}+02$ & $1.2363 \mathrm{E}+02$ \\
\hline 28 & $3.0691 \mathrm{E}+02$ & $3.7548 \mathrm{E}+02$ & $3.8378 \mathrm{E}+02$ & $5.2828 \mathrm{E}+02$ & $5.9336 \mathrm{E}+01$ \\
\hline 29 & $2.0343 \mathrm{E}+02$ & $2.0923 \mathrm{E}+02$ & $2.4777 \mathrm{E}+02$ & $5.7474 \mathrm{E}+02$ & $8.5165 \mathrm{E}+01$ \\
\hline 30 & $3.0133 \mathrm{E}+02$ & $6.3928 \mathrm{E}+02$ & $6.5187 \mathrm{E}+02$ & $1.2231 \mathrm{E}+03$ & $1.7909 \mathrm{E}+02$ \\
\hline
\end{tabular}

\section{B. Results for $30 D$}

Table II shows the computational results $f\left(x^{i}\right)+f\left(x^{*}\right)$ of the proposed algorithm for the $30 \mathrm{D}$ test problems. The goal is to minimize the given function.

In the case when $\mathrm{D}=30$, the behaviour of the algorithm is quite linear. Error value between optima reached and actual optima is less in the case of multimodular functions.

\section{Results for $50 D$}

Table III shows the results of Corr-GAA for the 50D test problems.Again the goal is to minimize the objective function.

Results are in the range of tens digit for multimodular function, which is considerably good given the high dimension value.
TABLE II

RESULTS FOR 30D

\begin{tabular}{|c|c|c|c|c|c|}
\hline Func. & Best & Median & Average & Worst & Std. \\
\hline 1 & $6.4577 \mathrm{E}+06$ & $2.4251 \mathrm{E}+07$ & $2.5610 \mathrm{E}+07$ & $6.6090 \mathrm{E}+07$ & $1.4139 \mathrm{E}+07$ \\
\hline 2 & $6.9482 \mathrm{E}+05$ & $1.9071 \mathrm{E}+06$ & $2.3068 \mathrm{E}+06$ & $8.3544 \mathrm{E}+06$ & $1.3497 \mathrm{E}+06$ \\
\hline 3 & $6.6224 \mathrm{E}+01$ & $8.2055 \mathrm{E}+03$ & $1.1352 \mathrm{E}+04$ & $4.8656 \mathrm{E}+04$ & $1.1490 \mathrm{E}+04$ \\
\hline 4 & $7.7537 \mathrm{E}+01$ & $1.2875 E+02$ & $1.2444 \mathrm{E}+02$ & $1.9488 \mathrm{E}+02$ & $2.9034 \mathrm{E}+01$ \\
\hline 5 & $2.0017 \mathrm{E}+01$ & $2.0078 \mathrm{E}+01$ & $2.0099 \mathrm{E}+01$ & $2.0365 E+01$ & 7.7163E-02 \\
\hline 6 & $9.6535 \mathrm{E}+00$ & $1.5204 \mathrm{E}+01$ & $1.5066 \mathrm{E}+01$ & $2.1249 \mathrm{E}+01$ & $2.2238 \mathrm{E}+00$ \\
\hline 7 & $1.1812 \mathrm{E}-02$ & 8.9899E-02 & $1.0099 \mathrm{E}-01$ & $2.3841 \mathrm{E}-01$ & $5.2430 \mathrm{E}-02$ \\
\hline 8 & $1.4946 \mathrm{E}-03$ & $2.1383 \mathrm{E}+00$ & 7.6764E-02 & $3.1672 \mathrm{E}-01$ & 4.8501E-01 \\
\hline 9 & $4.0795 \mathrm{E}+01$ & $7.0749 \mathrm{E}+01$ & $7.2160 \mathrm{E}+01$ & $1.2060 \mathrm{E}+02$ & $1.8722 \mathrm{E}+01$ \\
\hline 10 & $1.5406 \mathrm{E}+00$ & $4.5432 \mathrm{E}+00$ & $5.5124 \mathrm{E}+00$ & $1.4304 \mathrm{E}+01$ & $2.7289 \mathrm{E}+00$ \\
\hline 11 & $1.4452 \mathrm{E}+03$ & $2.5930 \mathrm{E}+03$ & $2.5344 \mathrm{E}+03$ & $3.7280 \mathrm{E}+03$ & $5.0916 \mathrm{E}+02$ \\
\hline 12 & $1.1234 \mathrm{E}-01$ & $2.2250 \mathrm{E}-01$ & $2.3239 \mathrm{E}-01$ & $4.4113 \mathrm{E}-01$ & $6.5916 \mathrm{E}-02$ \\
\hline 13 & $2.4677 \mathrm{E}-01$ & $3.8714 \mathrm{E}-01$ & $3.9693 \mathrm{E}-01$ & $6.2749 \mathrm{E}-01$ & $1.0180 \mathrm{E}-01$ \\
\hline 14 & $2.4763 \mathrm{E}-01$ & $3.5044 \mathrm{E}-01$ & $3.4731 \mathrm{E}-01$ & $7.7286 \mathrm{E}-01$ & $7.7415 \mathrm{E}-02$ \\
\hline 15 & $5.0598 \mathrm{E}+00$ & $1.2827 \mathrm{E}+01$ & $1.2612 \mathrm{E}+01$ & $2.6721 \mathrm{E}+01$ & $3.9222 \mathrm{E}+00$ \\
\hline 16 & $8.8509 \mathrm{E}+00$ & $1.0435 \mathrm{E}+01$ & $1.0292 \mathrm{E}+01$ & $1.1773 \mathrm{E}+01$ & 7.0379E-01 \\
\hline 17 & $4.1432 \mathrm{E}+05$ & $2.9471 \mathrm{E}+06$ & $3.1244 \mathrm{E}+06$ & $7.8472 \mathrm{E}+06$ & $1.6871 \mathrm{E}+06$ \\
\hline 18 & $6.0214 \mathrm{E}+01$ & $8.4578 \mathrm{E}+02$ & $1.7138 \mathrm{E}+03$ & $1.1525 E+04$ & $2.3301 E+03$ \\
\hline 19 & $5.8877 \mathrm{E}+00$ & $8.4243 \mathrm{E}+00$ & $1.3295 \mathrm{E}+01$ & $7.9096 \mathrm{E}+01$ & $1.6887 \mathrm{E}+01$ \\
\hline 20 & $4.3173 \mathrm{E}+03$ & $1.9607 \mathrm{E}+04$ & $2.3070 \mathrm{E}+04$ & $6.6281 E+04$ & $1.6611 \mathrm{E}+04$ \\
\hline 21 & $1.0935 \mathrm{E}+05$ & $5.6194 \mathrm{E}+05$ & $7.0784 \mathrm{E}+05$ & $3.1991 \mathrm{E}+06$ & $5.7446 \mathrm{E}+05$ \\
\hline 22 & $1.4839 \mathrm{E}+02$ & $5.4640 \mathrm{E}+02$ & $5.3992 \mathrm{E}+02$ & $9.7901 E+02$ & $1.8788 \mathrm{E}+02$ \\
\hline 23 & $3.1526 \mathrm{E}+02$ & $3.1589 \mathrm{E}+02$ & $3.1609 \mathrm{E}+02$ & $3.1923 E+02$ & $8.2848 \mathrm{E}-01$ \\
\hline 24 & $2.2695 \mathrm{E}+02$ & $2.3184 \mathrm{E}+02$ & $2.3383 E+02$ & $2.4787 \mathrm{E}+02$ & $4.8534 \mathrm{E}+00$ \\
\hline 25 & $2.0338 \mathrm{E}+02$ & $2.0997 \mathrm{E}+02$ & $2.1037 \mathrm{E}+02$ & $2.1973 E+02$ & $3.4074 \mathrm{E}+00$ \\
\hline 26 & $1.0029 \mathrm{E}+02$ & $1.0044 \mathrm{E}+02$ & $1.0045 E+02$ & $1.0066 \mathrm{E}+02$ & $1.2280 \mathrm{E}-01$ \\
\hline 27 & $6.5560 \mathrm{E}+02$ & $7.9604 \mathrm{E}+02$ & $7.8366 \mathrm{E}+02$ & $8.9620 \mathrm{E}+02$ & $8.4466 \mathrm{E}+01$ \\
\hline 28 & $7.8554 \mathrm{E}+02$ & $9.4148 \mathrm{E}+02$ & $9.3496 \mathrm{E}+02$ & $1.0694 \mathrm{E}+03$ & $9.1560 \mathrm{E}+01$ \\
\hline 29 & $2.1643 \mathrm{E}+02$ & $2.1816 \mathrm{E}+02$ & $2.1762 \mathrm{E}+02$ & $2.1843 \mathrm{E}+02$ & $8.3003 \mathrm{E}-01$ \\
\hline 30 & $6.0852 \mathrm{E}+02$ & $1.0718 \mathrm{E}+03$ & $1.3626 \mathrm{E}+03$ & $2.1571 \mathrm{E}+03$ & $6.1135 \mathrm{E}+02$ \\
\hline
\end{tabular}

TABLE III

RESULTS FOR 50D

\begin{tabular}{|c|c|c|c|c|c|}
\hline Func. & Best & Median & Average & Worst & Std. \\
\hline 1 & $1.2157 \mathrm{E}+07$ & $3.0690 \mathrm{E}+07$ & $3.3894 \mathrm{E}+07$ & $6.9101 \mathrm{E}+07$ & $1.2880 \mathrm{E}+07$ \\
\hline 2 & $1 \mathrm{E}+07$ & $9.0521 \mathrm{E}+07$ & $6 \mathrm{E}+07$ & $1.6384 \mathrm{E}+08$ & $2.8117 \mathrm{E}+07$ \\
\hline 3 & $6 \mathrm{E}+03$ & $2.5127 \mathrm{E}+04$ & 69E+04 & $5.6582 \mathrm{E}+04$ & $1.2232 \mathrm{E}+04$ \\
\hline 4 & HOE+02 & $2.0946 \mathrm{E}+02$ & $75 \mathrm{E}+02$ & $3.2532 \mathrm{E}+02$ & $4.1814 \mathrm{E}+01$ \\
\hline 5 & $0 \mathrm{E}+01$ & $2.0262 \mathrm{E}+01$ & $51 \mathrm{E}+01$ & $2.0543 \mathrm{E}+01$ & 6.6367E-02 \\
\hline 6 & $0 \mathrm{E}+01$ & +01 & $E+01$ & $E+01$ & $E+00$ \\
\hline 7 & 8.16 & & & $E+00$ & 8.3963E-02 \\
\hline 8 & 6.90 & & $7 \mathrm{E}+01$ & $E+01$ & $3.2347 \mathrm{E}+00$ \\
\hline 9 & $5 \mathrm{E}+01$ & & $\mathrm{E}+02$ & +02 & $3.5692 \mathrm{E}+01$ \\
\hline 10 & $E+01$ & & $\mathrm{E}+01$ & $5 \mathrm{E}+01$ & $1.4703 \mathrm{E}+01$ \\
\hline 11 & & & +03 & +03 & $5 \mathrm{E}+02$ \\
\hline 12 & & & & & $57 \mathrm{E}-02$ \\
\hline 13 & & & & -01 & $6 \mathrm{E}-02$ \\
\hline 14 & & & & & E-01 \\
\hline 15 & 01 & +01 & +01 & +01 & $6 \mathrm{E}+01$ \\
\hline 16 & & & & +01 & 4E-01 \\
\hline 17 & & & & +06 & $9.9954 \mathrm{E}+05$ \\
\hline 18 & & & -03 & +03 & $3.7273 \mathrm{E}+02$ \\
\hline 19 & & & & +01 & $1.4156 \mathrm{E}+01$ \\
\hline 20 & & -04 & +04 & +04 & $1.3626 \mathrm{E}+04$ \\
\hline 21 & 2.2 & & -06 & +06 & $2.4806 \mathrm{E}+06$ \\
\hline 22 & & & & +03 & $3.2604 \mathrm{E}+02$ \\
\hline 23 & & & & +02 & $1 \mathrm{E}+00$ \\
\hline 24 & & & & +02 & $9 \mathrm{E}+00$ \\
\hline 25 & & & & $\mathrm{E}+02$ & $5.2901 \mathrm{E}+00$ \\
\hline 26 & & & & $E+02$ & $4.9965 \mathrm{E}+01$ \\
\hline 27 & & & & +03 & $1.0527 \mathrm{E}+02$ \\
\hline 28 & 5.780 & 6.593 & & $E+03$ & $2.6679 \mathrm{E}+02$ \\
\hline 29 & $2.2797 \mathrm{E}+02$ & 2.864 & 2.68 & $\mathrm{E}+02$ & $3.0371 \mathrm{E}+01$ \\
\hline 30 & $1.0980 \mathrm{E}+03$ & $1.3689 \mathrm{E}+03$ & $1.3703 \mathrm{E}+03$ & $1.6389 \mathrm{E}+03$ & $1.8400 \mathrm{E}+02$ \\
\hline
\end{tabular}

\section{Algorithm Complexity}

The algorithms complexity is calculated based on all problem dimensions. A summary of the results is shown in Table IV, where $T 0, T 1$ and $\hat{T} 2$ are as specified in CEC 2014 [16]. Here, time is measured in milliseconds.

From the results it can be concurred that complexity of the 
TABLE IV

COMPUTATIONAL COMPLEXITY

\begin{tabular}{|l||l|l|l|l|}
\hline Dim. & T0 & T1 & $\hat{T} 2$ & $(\hat{T} 2-\mathrm{T} 1) / \mathrm{T} 0$ \\
\hline 10 & $9.00 \mathrm{E}+04$ & $2.61 \mathrm{E}+06$ & $1.69 \mathrm{E}+08$ & $1.85 \mathrm{E}+03$ \\
30 & $9.00 \mathrm{E}+04$ & $4.86 \mathrm{E}+06$ & $2.89 \mathrm{E}+08$ & $3.15 \mathrm{E}+03$ \\
50 & $9.00 \mathrm{E}+04$ & $7.38 \mathrm{E}+06$ & $4.39 \mathrm{E}+08$ & $4.79 \mathrm{E}+03$ \\
\hline
\end{tabular}

algorithm varies linearly with Dimension.

\section{E. Effect on variation of parameters}

Total number of parameters used is 6 . The parameters are as follows:: Probabilities used are $P_{c}, P_{m}, P_{x b}$ and $P_{e}$; and size of tables $T_{x b}$ and $T_{e}$ as $T$ and $R$ respectively.

a) Variation of Probabilities: Variation of results with respect to crossover probability $P_{c}$ and mutation probability $P_{m}$ is as expected of GAs. Slight increase of $P_{m}$ significantly changes the results because of the mutation method used.

Variation of results with respect to $P_{x b}$ i.e probability of archive $T_{x b}$ is directly proportional to the amount of exploitation done. Optimum value of $P_{x b}$ is between 0.4 to 0.7 . Very low values of $P_{x b}$ produces random variation of the results, as convergence rate becomes low. Very high values makes the results converge to a local optima.

b) Variation of archive size: By the use of table $P_{e}$ search space is explored during the beginning and then exploits during the end runs. But the amount of exploration is much higher than that of exploitation. Thus this parameter should be kept at an optimum value where there is a fine balance between exploitation and exploration. The optimum value is between 0.1 to 0.4 . Very low values of $P_{e}$ makes the results converge prematurely owing to the high convergence rate of the algorithm and very high value makes the results random owing to the randomness introduced by table $T_{e}$.

Size of $R$ should be less than $2 T$ as mentioned above. Both $R$ and $T$ are given as fraction of runs. Value of $R$ should be less considering the statements mentioned above. Very low value of $R$ and very high value of $T$ makes the results go to a local optima, whereas very high value of $R$ and low value of $T$ introduces high randomness. It should also be noted that when values of $R$ or $T$ are high enough to be comparable to $G_{\text {max }}$, then the tables fail to participate to its full potential.

\section{CONClusion}

In this paper we have demonstrated the use of correlation between two individuals in determining the best candidate and the use of predicted good fit individuals. Corr-GAA does not differ much from the basic GA model. The only additions of Corr-GAA are the use of one exploration archive and other exploitation archive and the new correlation based selection operator introduced. The interesting fact about the exploitation archive is that it changes from being exploitation in nature to being exploration with increasing number of runs.

This idea can be further extended in a number of dimensions. The weight of each gene obtained can be used during mutation to determine the mutation rate and the amount of mutation of each gene.

\section{REFERENCES}

[1] J. Holland. Adaptation in natural and artificial systems. 1975.

[2] D. E. Goldberg. Genetic algorithms in search, optimisation, and machine learning. 1989.

[3] M. Srinivas and L. M. Patnaik. Genetic algorithms: A survey. Computer, 27(6):17-26, 1994.

[4] K. De Jong. Learning with genetic algorithms: An overview. Machine learning, 3(2-3):121-138, 1988.

[5] M. Mitchell. An introduction to genetic algorithms. MIT press, 1998.

[6] D. Beasley, R. R. Martin, and D. R. Bull. An overview of genetic algorithms: Part 1. fundamentals. University computing, 15:58-58, 1993.

[7] S. N. Sivanandam and S. N. Deepa. Introduction to genetic algorithms. Springer Science \& Business Media, 2007.

[8] B. L. Miller. Noise, sampling, and efficient genetic algorithms. 1997.

[9] M. S. Arumugam, M. V. C. Rao, and R Palaniappan. New hybrid genetic operators for real coded genetic algorithm to compute optimal control of a class of hybrid systems. Applied Soft Computing, 6(1):38-52, 2005.

[10] M. Kaya. The effects of two new crossover operators on genetic algorithm performance. Applied Soft Computing, 11(1):881-890, 2011.

[11] J. Zhang and A. C. Sanderson. Jade: adaptive differential evolution with optional external archive. Evolutionary Computation, IEEE Transactions on, 13(5):945-958, 2009.

[12] R. Tanabe and A. Fukunaga. Success-history based parameter adaptation for differential evolution. In 2013 IEEE Congress on Evolutionary Computation (CEC), pages 71-78. IEEE, 2013.

[13] A. Trivedi, D. Srinivasan, S. Biswas, and T. Reindl. Hybridizing genetic algorithm with differential evolution for solving the unit commitment scheduling problem. Swarm and Evolutionary Computation, 23:50-64, 2015.

[14] S. Achiche and S. Ahmed-Kristensen. Genetic fuzzy modeling of user perception of three-dimensional shapes. Artificial Intelligence for Engineering Design Analysis and Manufacturing, page 101, February 2011.

[15] R. Storn and K. Price. Differential evolution-a simple and efficient heuristic for global optimization over continuous spaces. Journal of global optimization, 11(4):341-359, 1997.

[16] J.J. Liang, B. Y. Qu, and P. N. Suganthan. Problem definitions and evaluation criteria for the cec 2014 special session and competition on single objective real-parameter numerical optimization. Computational Intelligence Laboratory, Zhengzhou University, Zhengzhou China and Technical Report, Nanyang Technological University, Singapore, 2013. 